\title{
Zoning the protected area of Shahoo/Kosalan using RS and GIS
}

\author{
Farzam Hasti ${ }^{1}$, Haydar Rouhi $^{2}, \operatorname{loghman}$ Khodakarami $^{3}$, A. S. Mahiny ${ }^{4}$ \\ ${ }^{I}$ Master's degree graduate in Environment- land use planning, Gorgan University of Agricultural Sciences and \\ Natural Resources, (Iran). (farzam.hasti@gmail.com) \\ ${ }^{2}$ Master's degree graduate in Environment, Gorgan University of Agricultural Sciences and Natural Resources, \\ (Iran) \\ ${ }^{3}$ Assistant Lecturer at Faculty of Engineering, Koya University, Kurdistan Regional Government, Iraq \\ ${ }^{4}$ Associate Professor, Department of Environment, Gorgan University of Agricultural Sciences and Natural \\ Resources, (Iran)
}

\begin{abstract}
Zoning is the main part of planning principles, which is now considered as the most important tool in preserved areas management. This study has been carried out in the preserved area of Shahoo/Kosalan, located in Kurdistan Province (Iran). It seeks to examine the implication of remote sensing (RS) and geographic information system (GIS)in allocating optimal zones and resolving existing conflicts. Using satellite images of Landsat 8 (June, 14, 2015) and by the means of ecological niche factor analysis, land use maps and NDVI as well as wild goats habitat favorability maps were prepared. After database development in GIS, to actualize potentials of this area, 7 zones were selected. Following thatand according to experts, natural traits of the area, previous studies character models were written to integrate the parameters of each zone and develop MCE. After MCE development for each zone, MOLA was employed to finalize zoning. Results obtained from MOLA zoning reveal that positioning of the applications has been appropriately done, which in case of being operationalized, will prevent the existing conflicts.
\end{abstract}

Keywords:Zoning,RS, GIS, MCE, MOLA, Shaho/Kosalan

\section{Introduction}

Preserved area is defined as a location of natural resources such as jungles, grasslands, etc. which is protected to keep and proliferate animals and plants. In such areas, cutting trees, destruction, and hunting without license are prohibited. Unfortunately, due to extreme exploitation of grasslands for livestock productions, soil erosion, and destruction these areas are not properly protected. However, preserved areas possess plant and animal species diversity. Also, due to protective, research, educational, scientific and recreational aspects, preserved areasare of great importance for planners (Meith 2009).

Zoning is a purposeful effort which is made based on resource protection criteria (physical and biological) and proper development, which finally leads to making plan activities for each zone. Zoning is the main part of planning principles, which is now considered as the most important tool in preserved areas management (Walther, 1986; Sabtini et al, 2007).

Because of different goals of interest groups (local inhabitants, tourists, Tourism operators, and scientists), some conflicts are observed in preserved areas (Eagles, McCool \& Haynes, 2002). Thus, zoning in managing parks and preserved areas is a strategy by which the conflicts will reduce and opportunities are provided to take required steps (Walther, 1986). Reaching protective, research, educational, scientific and recreational goals is impossible without zoning. Today, the number of zones has reached 7 for different uses. Althoughthe names of zones are different from country to country, they do not differ in terms of goals.

Not also is zoning useful to protect biodiversity in managed areas, rareand endangered species as well as typical ecosystems, but it also plays a key role in sustainable development of natural resources reserves and achieving determined goals by IUCN for preserved areas (Liu \& $\mathrm{Li}, 2008$ ).

Since no research has been conducted in terms of multi objective land use allocation (MOLA) in Kurdistan, and also as Shaho/Kosalan area lacks zoning and management, this study seeks to planning and zoning this area using GIS and remote sensing.

Many studies have been conducted regarding GIS and MOLA in zoning areas. For example, Mahiny and Kamyab (2011) in a study, zoning a preserved area of Jahannama in Golestan Province, divided it into seven zones using MOLA model. Hajehforooshnia et al., (2011), in order to zoning Gamishlo preserved area (located in Isfahan, Iran), they, first, prepared and weighed different parameters using AHP method and then extracted proportionality layers utilizing multi criteria evaluation. Finally, MOLA module was employed to zoning protection, agriculture, renovation, and resuscitation layers. The results showed proper positioning of the zones in the area.

In another study, done in Gorgan and Kordkoy (Iran), MOLA was used for land preparation and allocation to specific uses with respect to ecologic and socio-economic capacities of the area. Finally, the area 
was divided into 7 uses including protected, agriculture, grassland, forestry, range management, urban and rural development, and hydrothermal and cold water aquaculture (Hasti et al., 2014).

\section{Materials and Methods}

\section{Studied area}

Studies area of this research is located in Sarvabad and Kamyaran towns, Kurdisan Province, west of Iran. Figure 1 shows the studied area false color combination of Landsat 8. Shaho/Kosalan includes 57189 hectares preserved area between east longitude 461126 and north latitude 35637 with UTM coordinates, zone 38 north.Shaho/Kosalan is a unique area of Kurdistan Province which has 224 Forest and pasture plant species of which 30 species are endangered. In this habitat, 17 bird, 23 mammal, and 17 reptile species have been identified out of which rare species like wild goats, panther, lynx, brown bear, and prey birds such as golden eagle could be mentioned.Due to aesthetic-recreational capacities such as hawraman historical village, Palangan historical village and water fall, Kosayhajij village, Sirwan River, bel spring and cultural-religious ritual of Pirshaliar, this area attracts a considerable number of tourists both inside and outside the country (Ahsani, 2006).

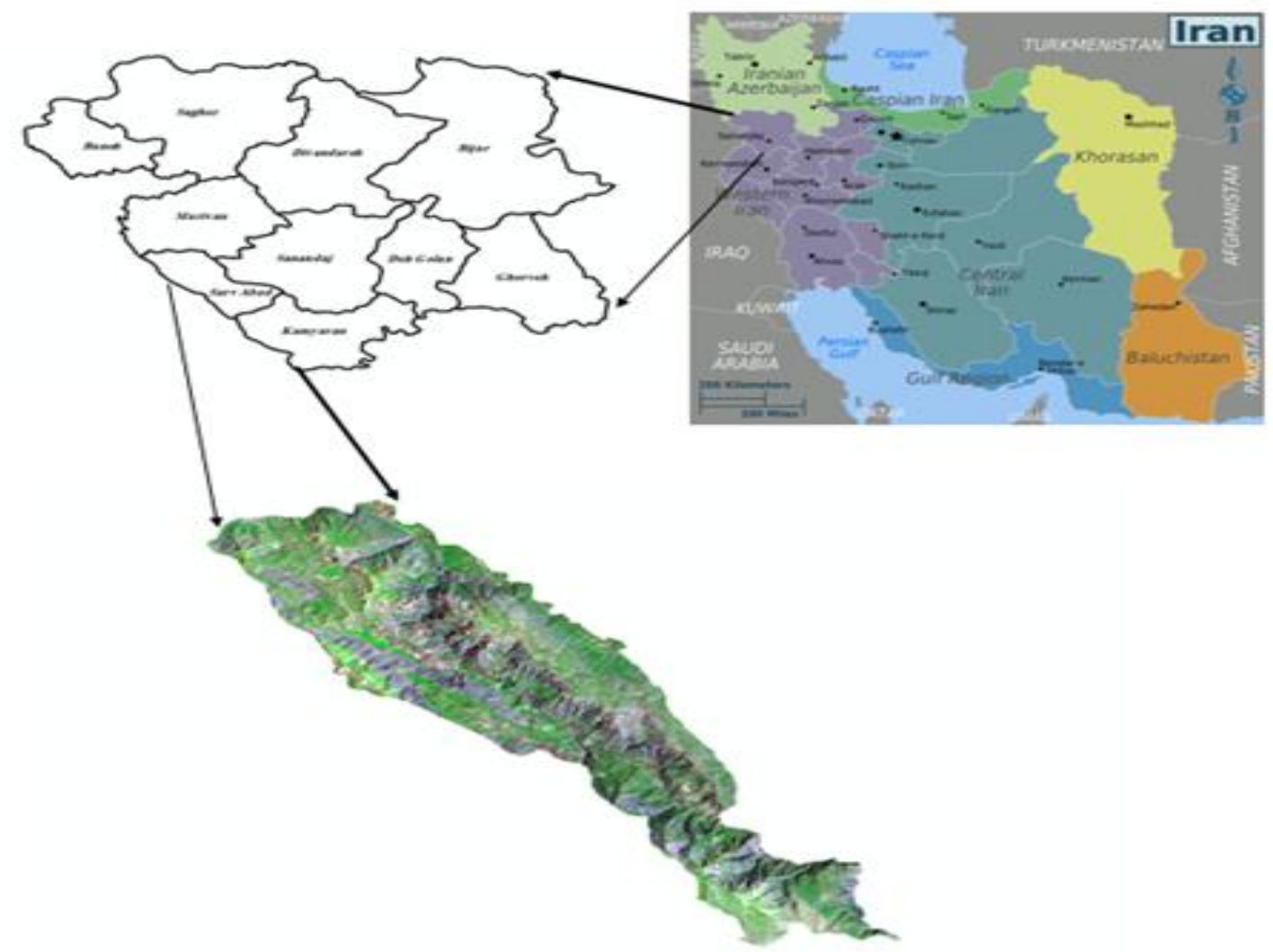

Figure1. Location of Shahu-kvsalan protected area

To better understand the natural features of the area, especially its unevenness (lowness and highness), Hillshade map was prepared using ARC GIS software version 10.1, done by DEM with 30 meter accuracy. In preparing this maple, the angle and height of the sun were considered 45 degree. To understand and manage the area in a better way while zoning, land use map was prepared by means of Landsat 8 images (14/06/2015) and maximum likelihood of supervised classification in ARC GIS software version 10.1. Finally, the accuracy of the map was examined by ground control points and using Kappa coefficient of 0.92 , the area was divided into forest and grassland, garden and agriculture, and rock and grassland.

\section{Database preparation for evaluation and zoning Shaho/Kosalan preserved area}

Digital layers employed in this study include as follows:

1. Digital Evaluation Model (DEM),Slopes,Drainage5. Geology,Vegetation type,Density of vegetation,Roads, Villages,springs and Surface water reserves,favorability of wildlife habitat,Soil, Soil erosion and Climate.

To prepare the map of vegetation density, normalized difference vegetation index (NDVI) and red and infra-red bands near Landsat 8 images were used in ENVI software version 5.1. Normal value of this index ranges 
between -1 and +1 . At next stage, NDVI map was classified as high, middle, and low density. Also to prepare the map of wildlife habitat favorability, the locations of wild goats, which live in the same location as panther, were recorded. Then, ecological niche factor analysis and Bio mapper program were used to prepare the map of wild goathabitats favorability. To analyze the sensibility and to construct information layers and to enter them to Bio mapper program IDRISI Selva was used. Required information layers for analysis in Bio mapper program can be classified as Work map and Eco-geographical maps. The layers first prepared and set in IDRISI Selva and then entered Bio mapper program:

1. Work map: dependent variable map or points of species presence raster map, which should be prepared in the form of Boolean (zero and one). Digit 'one' represents the points or areas where have been recorded in field work and indicates the locations of speciespresence (Hirzel et al., 2007). Preparing spatial distribution map of the target species needs filed work and data collection. In this study, sampling was done using random linear transect, direct observation or identifications of wild goat indices (dung, footprint, resting places) (Wespernic \& Remors, 2008). Sampling was done in fall and winter (2015) and similar transects, thatis 20 transects with a total length of $100 \mathrm{~km}$ were installed. Points of species presence were recorded by GPS.

2. Eco-geographical maps: Raster maps of bio-geographical variables affect species presence and are applied as independent variable. Bio-geographical variablesencompassthe positional factors of studied area, which describe quantitative outcomes of it (Hirzel et al., 2007).

The following 2 steps of preparing the map of bio-geographical independent variables are:

1. Outlining bio-geographical independent variables affecting target species presence

Raster maps of digital elevation model (using 30-meter contour line map) slope and direction (based on digital elevation model), villages in the vicinity of the area, water resources including permanent and seasonal springs and rivers, roads, and normalized difference vegetation index (NDVI) were prepared.

2. Rasterization of maps in IDRISI Selva and considering the sameness of all map formats

Integration of the maps means being identical in terms of coordinate system, geographical longitude and latitude, layer type, layer format, number of rows and columns, and other parameters existing in variable information table.

\section{Data Analysis}

The steps taken in Bio mapper program are as follows:

1. Calling bio-geographical and species presence maps 2. Quantifying the layers: to make the maps biologically significant, they must be quantified.To do this, circular and direct analyses are used. 3. bio-geographical and species presence maps must be normally distributed; otherwise, Box-Cox normalization method, which is performed in Bio mapper program $\mathcal{}$, is recommended. 5. Making all independent and dependent variables map in order to make sure if they cover the same area.Uniformity and usability comparison of maps is possible through "verify" path. In this operation, the sameness of field cells values etc is examined. Non-identical layers are identified in this step. 6. Examining the correlation between bio-geographical maps using correlation matrix. At this step, correlated layers (here, correlation over 0.85 ) should be omitted because this analysis requires independent and non-correlated variables. In ecological niche factor analysis, if two variables are correlated, both will appear with the same coefficient in the model. 7. Ecological niche factor analysis implementation 8 . Calculating required factors to prepare habit proportionality map 9. Estimating habitat proportionality map.

At last, wild goat habitats favorability map could be classified as high and low habitat values classes. This process can also be applied for other wild species.

\section{Zoning Shaho/Kosalan preserved area}

Zoning of Shaho/Kosalan preserved area was done using multi criteria evaluation, which contains the following steps:

1. Identifying and defining zones for the respected area. 2. Identifying and providing information layers related to each zone. 3. Providing integrated information layers model for each zone separately. 4. Determining the weight of model variables. 5. Integrating information layers and estimating the capacity of the area for each zone. 6. Comparing the capacity of the locations in the area to select the best zone (using a proper land preparation).

Multi Criteria Evaluation (MCE) is a non-eco-systemic method for evaluating environment capacity, in which the layers have been integrated for different uses. Then, decision making or preparation which means applying competitor uses for each land unit, are done based on land preparation strategies. MCE analysis is done using geographical computer system, IDRISI SElva software. MCE is done in different ways, out of which we employed weighted linear combination one to integrate layers and prepare capacity map of the area for each zone.To enable preserved area of Shaho/Kosalan, however, the following 7 zones were defined and for each one a character model was designed. 


\section{Safe zone character model}

The suitable arenas for safe zone should have the following qualities:

Slope over $70 \%$, the maximum distance from river: $150 \mathrm{~m}$, moderate to high vegetation density, to observe the distance of $150 \mathrm{~m}$ within the roads, $30 \mathrm{~m}$ distance from springs, Stones with very high sensitivity to erosion and destruction, to observe the distance of $250 \mathrm{~m}$ within villages and wild habitats (Mahiny\& Kamyab, 2011).

\section{Preserved zone character model}

All parameters of this zone are similar to of safe one, but with lower sensitivity. After preparing safe zone map, appropriate zones for preserved zone were separated and reset to the range of 0-255. This zone will be a preserver for the safe zone (Mahiny\& Kamyab, 2011).

\section{Wide recreation zone character model}

The arenas of recreation zone should possess the following features:

To have stones resistant to walking, to observe the distance of $250 \mathrm{~m}$ within river, moderate to low vegetation density, to observe the distance of minimum $250 \mathrm{~m}$ within wild habitats, the ridge of the mountains to see natural sceneries, maximum $15 \%$ of slope, distance of road within $100 \mathrm{~m}$ because after this distance the favorability will reduce (Mahiny\& Kamyab, 2011).

\section{Centralized recreation zone character model}

The suitable arenas for centralized recreation zone should have the following qualities:

To have rocks resistant to camping and children's play, to observe the distance of minimum 100m and maximum $200 \mathrm{~m}$ within springs and rivers $100 \mathrm{~m}$ because after $200 \mathrm{~m}$ of distance the favorability will reduce, moderate vegetation density, to observe the distance of $100 \mathrm{~m}$ within ridge of mountains, maximum $15 \%$ of slope, to observe the distance of $100 \mathrm{~m}$ within villages and roads because more than $100 \mathrm{~m}$ of distance will reduce favorability, to exclude wild habitat, to observe the maximum distance of $1000 \mathrm{~m}$ within creational, historical, and tourist centers (Mahiny\& Kamyab, 2011).

\section{Renovation zone character model}

In the arenas of this zone, there have been some activities such as agriculture (farmlands and gardens) and grazing. Such zones are characterized by low vegetation density as well as the distance of $250 \mathrm{~m}$ within roads, villages, farmlands, and gardens (Mahiny\& Kamyab, 2011).

\section{Cultural-historical zone character model}

Cultural, historical, and religious centers (such as Hawraman historical village, Kosae Hajij village, and Palangan village etc) are appropriate for this zone. This zone has stone resistant to construction, distance within roads: $1000 \mathrm{~m}$, lacks wild habitats, has low to moderate vegetation density, maximum slope of $30 \%$. If the distance within the springs and rivers increases, the favorability will decrease (Mahiny\& Kamyab, 2011).

\section{Special uses zone character model}

The suitable arenas for special uses zone ought to own the following characteristics:

To have a minimum and maximum distances of 500 and $3000 \mathrm{~m}$, respectively within springs and rivers, stones resistant to construction, low to moderate vegetation density, , the minimum and maximum distances of 300 and $7000 \mathrm{~m}$, respectively within villages, slope of 15\%, and lacks wild habitats (Mahini \& Kamyab, 2011).

Using each zone character model, the zones factors were phased and finally utilizing weighted linear integration (equation 1), the factors were integrated and the favorability maps were prepared.

$\mathrm{S}=\Sigma \mathrm{i}=1{ }_{\text {to }} \mathrm{W}_{\mathrm{i}} \mathrm{X}_{\mathrm{i}} \Pi \mathrm{C}_{\mathrm{i}}(1)$

Where, $\mathrm{S}$ represents proportionality of given zone, Wi weight of each phased layer, Xi phased layer or factor, Ci Boolean layer or limitation, $\Pi$ multiplication sign.

AHP in IDRISI Selva softare was used to weigh the layers of each zone. In this study, multi objective land use allocation (MOLA) in IDRISI Selva software was used in zoning. In this method, we need to enter descriptive titles of a weight for each goal, map ranking, required area for each use. This method is mainly based on selecting zones which have the highest value for each arena and have enough space as well. Therefore, taking parameters like size of the zone and positioning at the whole area space, a kind of simultaneous and multi-dimensional comparison is made. Also, different combinations are done repeatedly so that the required conditions are met to achieve the best possible zoning. Based on this process, incompatible uses are identified and the best is chosen among them which lead to a primary zoning.

Following that, different zones which are still conceptually contradicted are finally modified. To do this, post-processing function like filters, parameters such as proximity,remoteness, size, and shape of spot will 
be used. Consequently, a finalized zoning will be obtained which includes all contributing factors, which can be prepared through map format.

In the current study, in order to implement MOLA land proportionality maps were first ranked.

In the next step, AHP was employed to determine required weight for each use. Then, in addition to ranking and weighing each use, the required space for each use was specified. According to experts and different factors such as ecological conditions of the area, the importance of use, existing policies in the area and so on, required space was determined for each zone. This, in fact, is a kind of secondary weighing, which affects land preparation process.

Diagram (1) shows the overview of research stages:

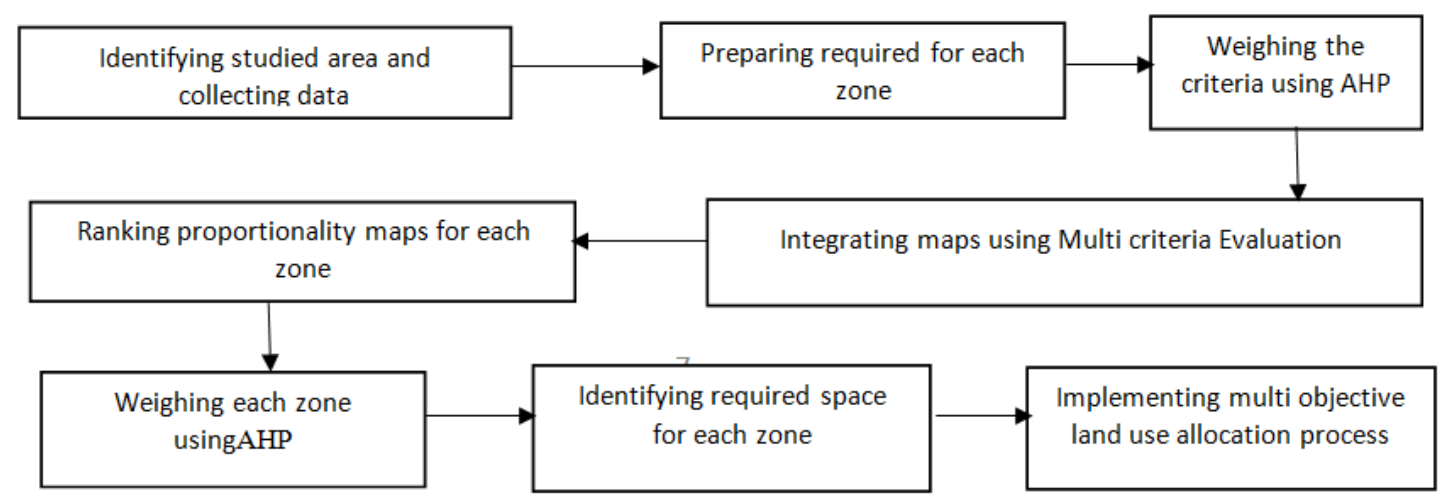

III. Results

Hillshade, NDVI, Habitat Suitability, and land use maps are shown in Figure 2.

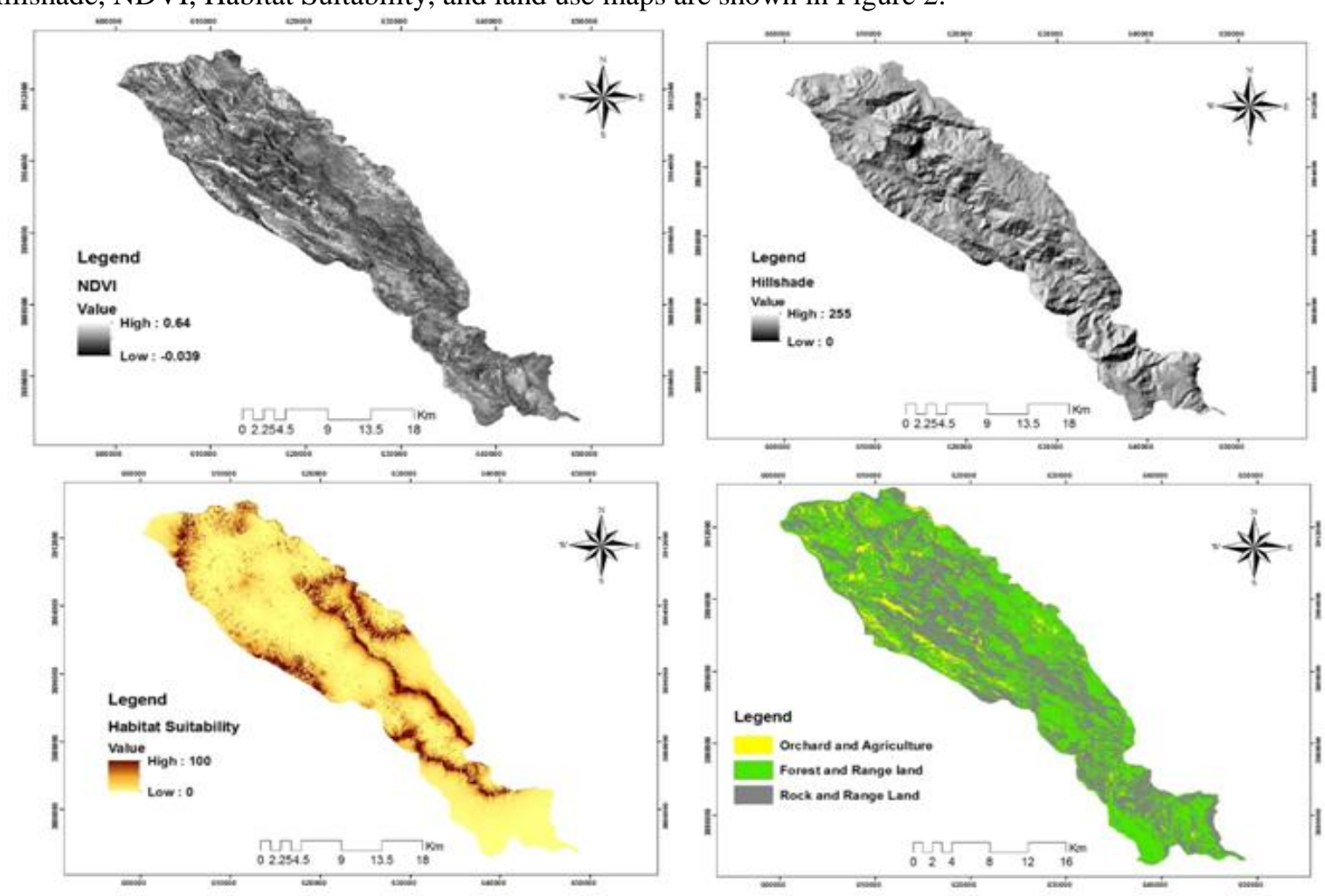

Figure 2:Hill shade, NDVI,Habitat Suitability, and Land Use. 
As mentioned, to prepare the maps of each zone capacity environment MCE was used. Figure 3 shows MCE prepared maps for each zone.

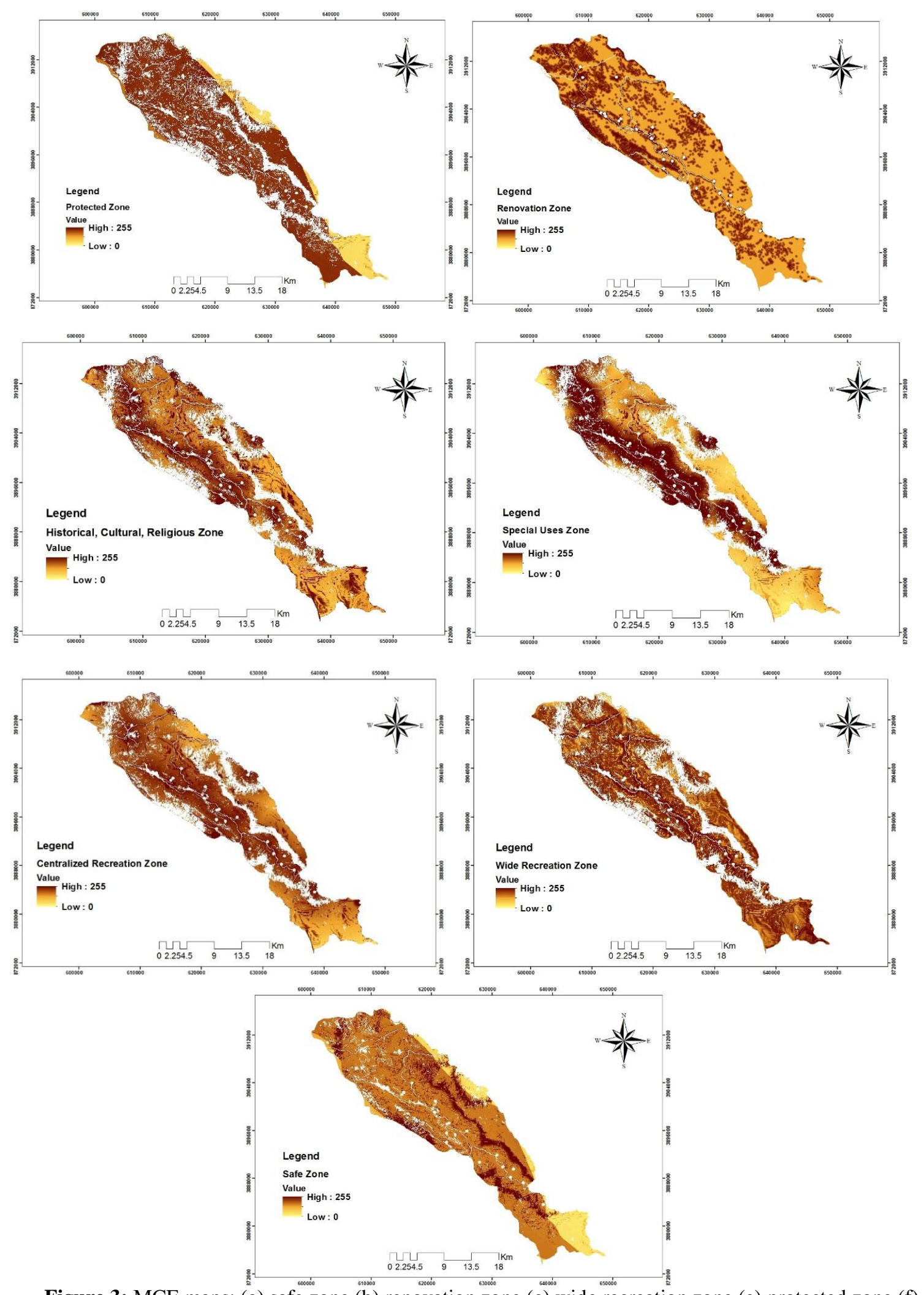

Figure 3: MCE maps: (a) safe zone (b) renovation zone (c) wide recreation zone (e) protected zone (f) historical, cultural, religious zone (g) special useszone (i) Centralized recreation zone. 
Considered weights and areas to finalize Shaho/Kosalan preserved area zoning using MOLA model are shown in Table 1.

\begin{tabular}{|c|c|c|c|}
\hline Row & Zone & weights(AHP) & Areas(cell) \\
\hline 1 & safe zone & 0.40 & 125000 \\
\hline 2 & renovation zone & 0.13 & 3000 \\
\hline 3 & wide recreation zone & 0.12 & 135000 \\
\hline 4 & protected zone & 0.20 & 321500 \\
\hline 5 & historical, cultural, religious zone & 0.03 & 1558 \\
\hline 6 & Centralized recreation zone & 0.08 & 2000 \\
\hline 7 & special uses zone & 0.03 & 3000 \\
\hline total & & 1 & 618058 \\
\hline
\end{tabular}

Finally, MOLA module was implemented and given post-processing was applied too. Figure 4 shows the final zoning of preserved Shaho/Kosalan area.

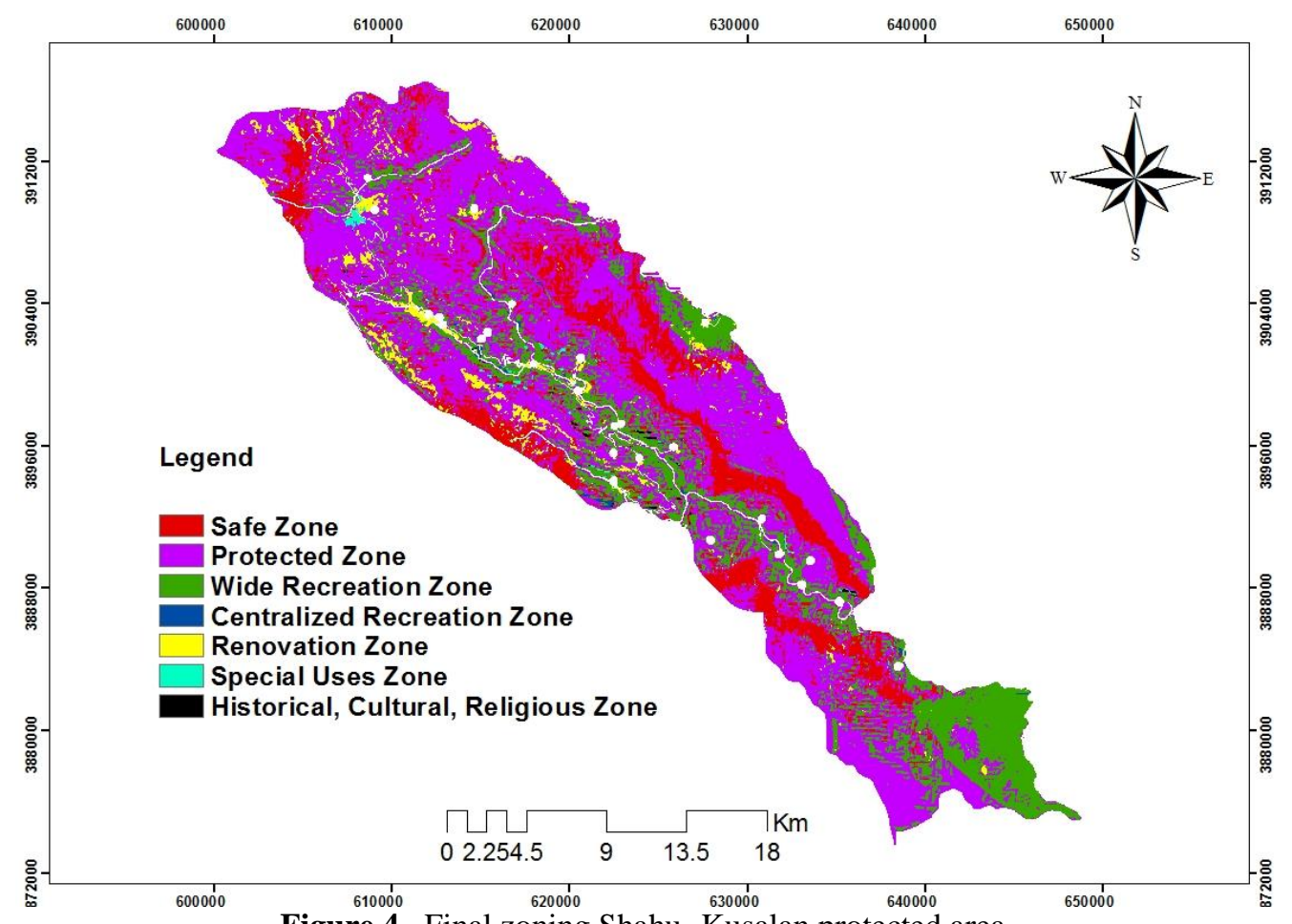

Figure 4. Final zoning Shahu- Kusalan protected area

\section{Discussion and conclusion}

Examining MOLA map of positioning zones, we can find that zone positioning has appropriately been done. Wild habitats have been properly located in safe zone. On the other hand, as all parameters of safe zone are similar to preserved zone (but with lower sensitivity), preserved zone plays a preserver role for safe zone. This zone has fully surrounded safe zone. Arenas allocated to wide recreation zone, in addition to having recreational potentials such proximity to natural sceneries, are located near preserved zones. This, due to preserving role of preserved zone, will resolve the conflict between wide recreation and safe zones. Gardens and farmlands are allocated to the renovation zone; therefore, by taking actions such as renovating farmlands, gardens, and grasslands challenges among local interest groups could be relatively reduced. Through proper positioning special uses zone close to preserved zones and their convenient access to roads and villages, we could enjoy implications such as establishing environmental monitoring stations in this zone. Finally, arenas allocated to centralized recreation and cultural, historical, religious zones in the vicinity of Hawraman, Kosae Hajij, and Palangan villages have high cultural, historical, and tourist capacities including Pirshaliar ritual and Kosae Hajij tomb. On the other hand, MOLA does not consider the neighborhood. That is, there is the possibility that dissimilar uses are selected together. This is because itis a pixel-based method and pixilated selection is donein this method. To solve this problem, an acceptable and separator use or buffer could be created among dissimilar uses. However, such a problem is not so noticeable in this study. In MOLA land preparation pixels are used to position uses and each pixel that has the intended features in terms of ranking, weight, and space to a use, it will be specified to the very use. This will result in scattered spots, which is considered as a demerit of MOLA module. This problem could be solved through pre-processing and post- 
processing such as filters as well as considering factors such as remoteness and proximity of spots and their sizes. To this purpose, in this study, $3 * 3$ post-processing filter function and Median function were used, which relatively solved the problem of spots dispersion more logically. Since this process is done in geographical computer system, it enables the user to replicate. The obtained results could be reviewed and based on the area's situation, some changes could be made for parameters and gain the results that most interest groups agree upon and is compatible with area's capacity.

\section{References}

[1]. Ahsani, N. Yakhshki, A. Awladi. J. Study potential environmental of Kusalan regional be based on iucn criteria using satellite imagery, 2006. Master's thesis, University of Mazandaran, Department of Natural Resources. 81 pages.

[2]. Alberti, M., (1999);«Modeling the urban ecosystem: a conceptual framework. Environment and Planning» B: Planning and Design 26: 605-630.

[3]. Costanza, R..; Voinov, A.( 2009); «Landscape Simulation Modelling», Springer, New York, USA.

[4]. Eagles, P. F. J., McCool, S. F., \& Haynes, C. D. A. (2002). IUCN. Gland, Switzerland and Sustainable tourism in protected areas: Guidelines for planning and management. Cambridge, UK: IUCN.

[5]. Hajehforooshnia, S.; Soffianian, A.; Salman Mahiny, A.; Fakheran, S. (2011);«Multi objective land allocation (MOLA) for zoning Ghamishloo Wildlife Sanctuary in Iran», Journal for Nature Conservation, 19: 254-262.

[6]. Hasti, F. SalmanMahiny, A.R, Jolay, R. Aghili, S.M. 2014. Application of Geographic Information System (GIS) in the allocation of land use (area of study: Gorgan and Kordkoy). First National Conference on Geography, tourism, natural resources and sustainable development. 2014, Tehran. http://www.civilica.com/Paper-NCGTSD01-NCGTSD01_495.html

[7]. Hirzel, A. H., Hausser, J., and perrin, N. 2007. Biomapper 4.0, Laboratory for Conservation Biology, Department of Ecology and Evolution, University of Lausanne, Switzerland. URL, Viewed 10 November 2010. <http://www2.unil.ch/biomapper>.

[8]. Liu, X., \& Li, J. (2008). Scientific solutions for the functional zoning of nature reserves in China. Ecological Modeling, 215, 237246.

[9]. Meith, N., United Nations Environment Program. 2009. Ecosystem management program a new approach to sustainability, Publishing Services Section, Nairobi, Kenya, ISO 14001: manufacturer.

[10]. Sabatini, M. D. C., Verdiell, A., Iglesias, R. M. R., \& Vidal, M. (2007). A quantitative method for zoning of protected areas and its spatial ecological implications. Journal of Environmental Management, 83, 198-206.

[11]. SalmanMahiny, A.R and . kamyab, H.R. 2013. "Remote sensing and geographical information systems with Idrisi program" (translation), by Eastman, c. Ronald, Mhrmhdys Press, 596 p.

[12]. SalmanMahiny, A.R. kamyab, H.R. 2012. Applied Remote Sensing and GIS with Idrisi. (Translated) written by J Ronald Eastman. Publishing Mehr Mahdis (Iran). $596 \mathrm{p}$

[13]. Voinov, A.; Costanza, R..; Wainger, L.; Boumans, R.; Villa, F.; Maxwell, T.; Voinov, H.(1999);«Patuxent landscape model: integrated ecological economic modeling of a watershed», Journal of Ecosystem Modelling and Software, 14: 473-491.

[14]. Vospernik, S., and Reimoser, S. 2008 . Modelling changes in roe deer habitat in response to forest management. Forest Ecology and Management. 255: 530-545.

[15]. Walther, P. (1986). The meaning of zoning in the management of natural resource lands. Journal of Environmental Management, $22,331-344$. 